\title{
Teaching, Designing, and Sharing: A Context for Learning Objects
}

\author{
Mimi Recker, Jim Dorward, Deonne Dawson, Xin Mao, Ye Liu, \\ Bart Palmer, Sam Halioris, and Jaeyang Park \\ Utah State University, Logan, UT, USA
}

\author{
Mimi.Recker@usu.edu Jim.Dorward@usu.edu \\ Deonne.Dawson@usu.edu Xin.Mao@usu.edu Ye.Liu@usu.edu \\ Bart.Palmer@usu.edu Sam.Halioris@usu.edu \\ Jaeyang.Park@usu.edu
}

\begin{abstract}
This article describes a professional development model and a set of tools intended to increase teachers' capacity for the design of instructional activities using learning objects. It then reports preliminary findings from studies involving teachers $(n=41)$ who participated in the professional development workshops based on the model. Findings suggest that participants saw many potential benefits of using online resources in support of teaching, including their convenience and currency. In terms of creating learning activities for their students, the most common use mentioned was for enrichment purposes. Analyses also showed that participants seemed to prefer to use small granularity resources. However, despite this enthusiasm, post-workshop usage was generally low. Participants also identified barriers in using online resources. These included lack of technology access and literacy, and difficulties in managing the overabundance of resources and their varying quality. Participants also mentioned the importance of accessing online resources for research purposes.
\end{abstract}

Keywords: Learning Objects, learning resources, teaching, designing, sharing, context

\section{Introduction}

Recent widespread availability of educational resources on the World-Wide Web holds great potential for transforming education. In science education, for example, students can now access real-time images from space exploration. They can also download data and partner with other students and scientists to analyze simulations of complex weather events (Marlino, Sumner, Fulker, Manduca, \& Mogk, 2001). In mathematics, students can interact with virtual tools and manipulatives that help make abstract concepts more concrete (Dorward \& Heal, 1999). Teachers

Material published as part of this journal, either on-line or in print, is copyrighted by the publisher of the Interdisciplinary Journal of Knowledge and Learning Objects. Permission to make digital or paper copy of part or all of these works for personal or classroom use is granted without fee provided that the copies are not made or distributed for profit or commercial advantage AND that copies 1) bear this notice in full and 2) give the full citation on the first page. It is permissible to abstract these works so long as credit is given. To copy in all other cases or to republish or to post on a server or to redistribute to lists requires specific permission and payment of a fee. Contact Publisher@ijklo.org to request redistribution permission. can effectively and efficiently tailor instructional activities to meet curriculum standards and the unique interests and educational needs of their students. In short, through interacting with Web content, students can now engage in highly personalized learning experiences, instead of relying on the one-size-fits-all textbook.

In recognition of this potential, several large-scale initiatives are developing 
repositories (or, digital libraries) containing catalogued learning objects (or, online learning resources). Key objectives are to provide teacher and learner access to high-quality learning objects in order to help improve the effectiveness and efficiency education (Wattenberg, 1998; Zia, 2001).

Leaders in these initiatives include:

- the National Science Digital Library (htttp://www.nsdl.org), funded by the United States National Science Foundation. In early 2005, the NSDL contained over 800,000 learning resources, collected from approximately 500 partner libraries;

- the Australian Le@rning Federation (http://www.thelearningfederation.edu.au);

- the European Union's Ariadne Foundation (http://www.ariadne-eu.org/);

- EduSource Canada (http://www.edusource.ca).

Despite the existing capabilities and implications for teaching and learning, little is known about how teachers view their roles in terms of adapting, designing, and reusing learning objects in diverse classroom situations, or how teachers' knowledge and skills are changed as a result of their interactions with these technologies and resources. Even less is known about impact on students. Indeed, an implicit assumption of these initiatives is that teachers and learners will access and use these technologies in unproblematic and seamless ways. Unfortunately, the history of educational technology suggests that this is seldom the case (Cuban, 2001). Instead, systems that must cross many institutional boundaries (such as school settings) rarely do so in transparent ways (Agre, 2003).

In this paper, we take the view that teaching and learning can be a creative, constructive process in which learning objects, such as those found in the NSDL, can play an important role. Teachers with ready access to unlimited high-quality learning objects become designers who adapt and customize learning objects to fit their local needs and context (Brown \& Edelson, 2003; Dede, 2003). In this context, learning objects become catalysts for creating locally relevant instructional solutions to support learning.

Toward this end, we describe a professional development model and a tool intended to increase teachers' capacity for the design of learning activities. As part of their design activities, teachers learn to use a simple end-user authoring service, called the Instructional Architect (IA). The IA helps users, particularly teachers, find, select, sequence, and annotate learning objects. With the IA, users can create personal collections of instructional activities, lectures, lesson plans, study aids, or any kind of instruction around learning objects (Recker, Dorward, \& Reinke, 2003).

As we will describe, use of the Instructional Architect in teacher development programs makes it easy to engage teachers in design activities using learning objects. In addition, analyses of resulting instructional projects provide a level of detail about teacher usage typically not available from standard instruments such as surveys and web server logs.

We then report preliminary findings from studies involving two groups $(n=41)$ of mathematics and science teachers who participated in the professional development workshops that focused on designing instruction using learning objects and the IA. Findings emerge from two sources of data: qualitative analyses of participants' pre and post workshop comments about uses of learning objects; and quantitative analyses of usage of learning objects in projects designed by teachers during and after the workshops. The focus of the analyses was on two related questions: 1) what are the attitudes of participants regarding the use of learning objects in support of teaching and design; and 2) how did they design instructional projects using learning objects? 
This paper is organized as follows. We first discuss the theoretical framework underlying our work and then describe our approach to supporting teachers as designers of instructional activities. We describe the methodology used in the studies and present preliminary findings. We conclude with a discussion of the studies' limitations and suggestions for future research.

\section{A Note about Language}

In the remainder of this paper, we avoid using the term 'learning object'. We do this for several reasons. First, the term has no single, clear, and unambiguous definition (Friesen, 2003). Second, the term implies that the learning is solely a property of the object. Finally, the term is unfamiliar to most practitioners. Instead, we prefer the term 'learning resource,' as its meaning seems better understood by teachers (Recker et al., 2005; Recker, Dorward, \& Nelson, 2004). More importantly, it implies that learning is jointly constituted in terms of the resources, people, practices, and values of the embedding context.

Similarly, we prefer using the term 'digital library' in lieu of 'repository'. This term better highlights the institutional nature of the enterprise, comprised of both managed, cataloged, and curated content, as well as the different social roles of the people involved (Agre, 2003). For example, digital libraries often provide access to online reference librarians, as well as discussions spaces.

\section{Theoretical Framework}

The image of teaching proposed in this paper is one in which teachers take advantage of the vast wealth of online resources to design and enact learning activities. Resources become the building blocks of learning activities, as teachers adapt and implement them in ways suitable to their local context.

This view is not necessarily novel and is aligned with a constructivist philosophy. It is also similar to ideas proposed of the teacher as bricoleur. However, what is novel is the recent abundant availability of high-quality, online resources for learning, such as provided by the NSDL. As such, it has become much more feasible for teachers to access and use these resources in their classrooms.

However, not all teachers naturally view their practice as design. For example, teachers' beliefs and their pedagogical philosophies will impact their use of such resources (Becker, 2000). Teachers with little teaching experience or a low comfort with subject matter will perhaps be less likely to adapt resources, and more likely to use them unchanged.

In addition, the nature of the resource provides affordances and constraints on its adaptation and use. For example, the granularity (or size) of a resource impacts adaptation (Wiley, Recker, \& Gibbons, 2000). Because of many internal dependencies, large resources are intended to be used with little modifications or additional effort, and the number of contexts in which they can be applied is small. For example, a semester-long course in geology is probably best used unchanged because of the many interdependencies between course components. Conversely, small, selfcontained resources afford greater teacher improvisation and adaptation in a wider range of situations. For example, a simple graphing calculator applet can be used in a wide range of mathematical contexts.

In sum, complex relationships exist between users, their social practices, attitudes, and values, and learning resources. Too often, a narrow focus on tool development tends to obscure these interconnections and, as a result, oversimplifies the design problems (O'Day \& Nardi, 2003). 


\section{Our Approach}

In the research described in this paper, we have taken a two-pronged approach for addressing teacher design with learning resources. First, employing human-centered, iterative design techniques (Nielsen, 1993), we have designed an end-user authoring tool, called the Instructional Architect (IA), that supports teachers in discovering and selecting learning resources in order to design instructional activities.

Second, we developed a teacher professional development model to help them learn to design with learning resources. The model includes a hands-on, collaborative, and design-based workshop component. These are described in the next section.

\section{The Instructional Architect: A Digital Library Service}

The Instructional Architect (IA.usu.edu) is an end-user authoring service intended to support the design of instructional activities using resources in the National Science Digital Library (www.nsdl.org) and elsewhere on the WWW. The IA enables users (primarily teachers) to discover, select, and design instruction (e.g., lesson plans, study aids, homework) using online learning resources. In this way, the IA is intended to increase the utility of online learning resources for the classroom educators (Recker et al., 2003).

The IA offers several major usage modes. First, in the 'my resources' area of the IA, users can search for resources in the NSDL. Queries are sent to the NSDL search interface, which searches the union metadata repository. This metadata repository is comprised of metadata records harvested via OAI-PMH from participating NSDL digital libraries (Lagoze, 2002). The standard metadata set used by the NSDL repository is an extension of the Dublin Core set of 15 basic elements (Dublin Core Metadata Initiative, 2002). Item-level and collection level metadata records from participating libraries are normalized or cross-walked to the NSDL standard set. Users can also perform an advanced search in the IA, where they can narrow their search by restricting the Dublin Core FORMAT metadata field.

Metadata records for matching resources are displayed to users in an abbreviated form (title, creator, brand, and description). After browsing these results and viewing resources, users can select and save pointers to desired resources for further use. Users can also select any Web resource by entering its URL in the IA, and adding it to their list of saved resources. Of course, these Web resources do not have associated metadata records. Users can also organize their selected records in folders. Finally, users can add comments about any saved resource. Comments about a resource then become publicly viewable to anyone who chooses to view the metadata for that resource.

Figure 1 shows an example screen shot of the saved resources for a user. These have been organized into several folders, called 'Tangrams' and 'Weather'.

Second, in the 'my projects' area, users can create web pages in which they select a look and feel for their project, and input selected resources and accompanying text. Figure 2 shows a screen shot of a project undergoing development. 


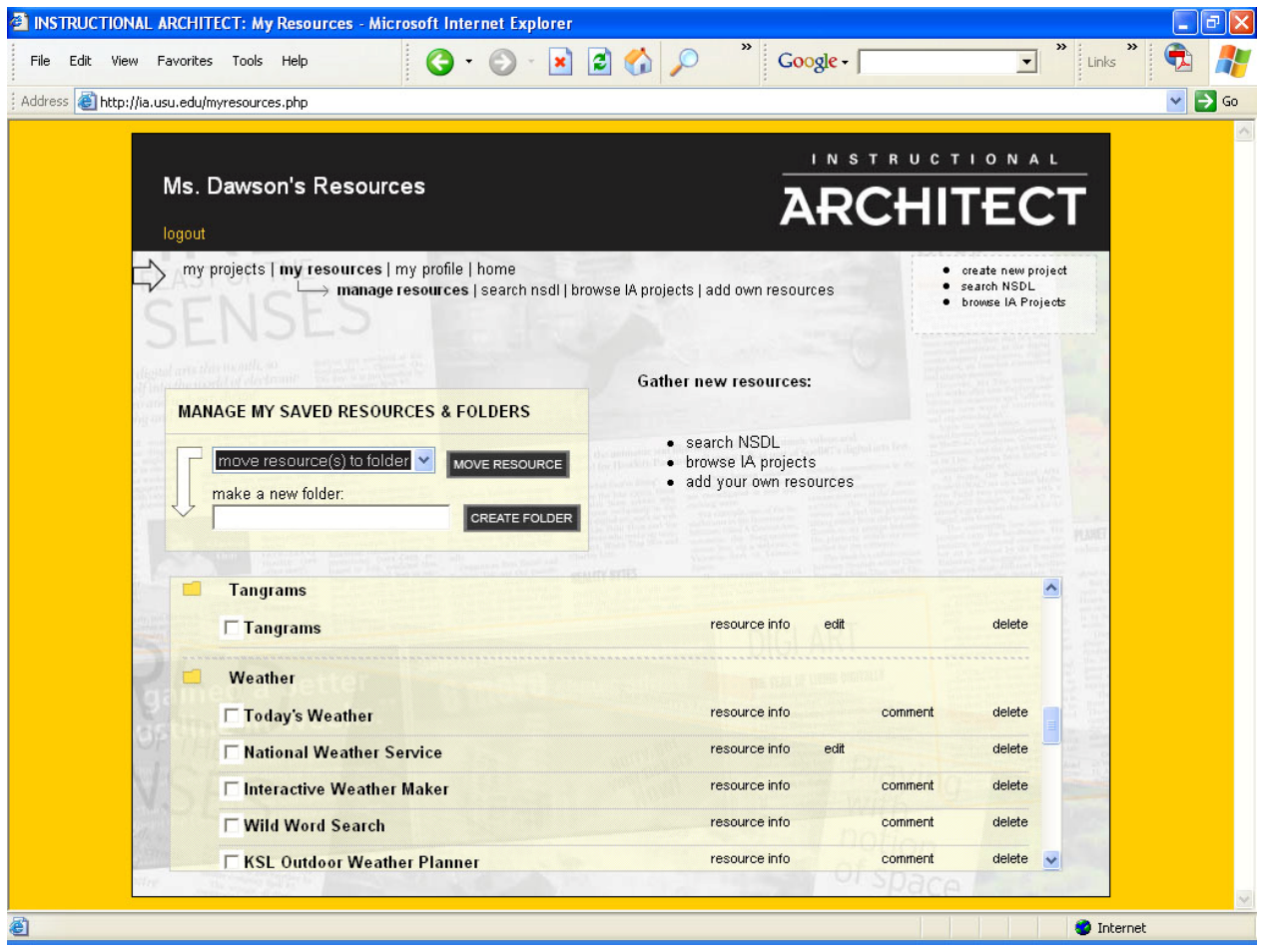

Figure 1: A user's saved resources, organized in two folders.

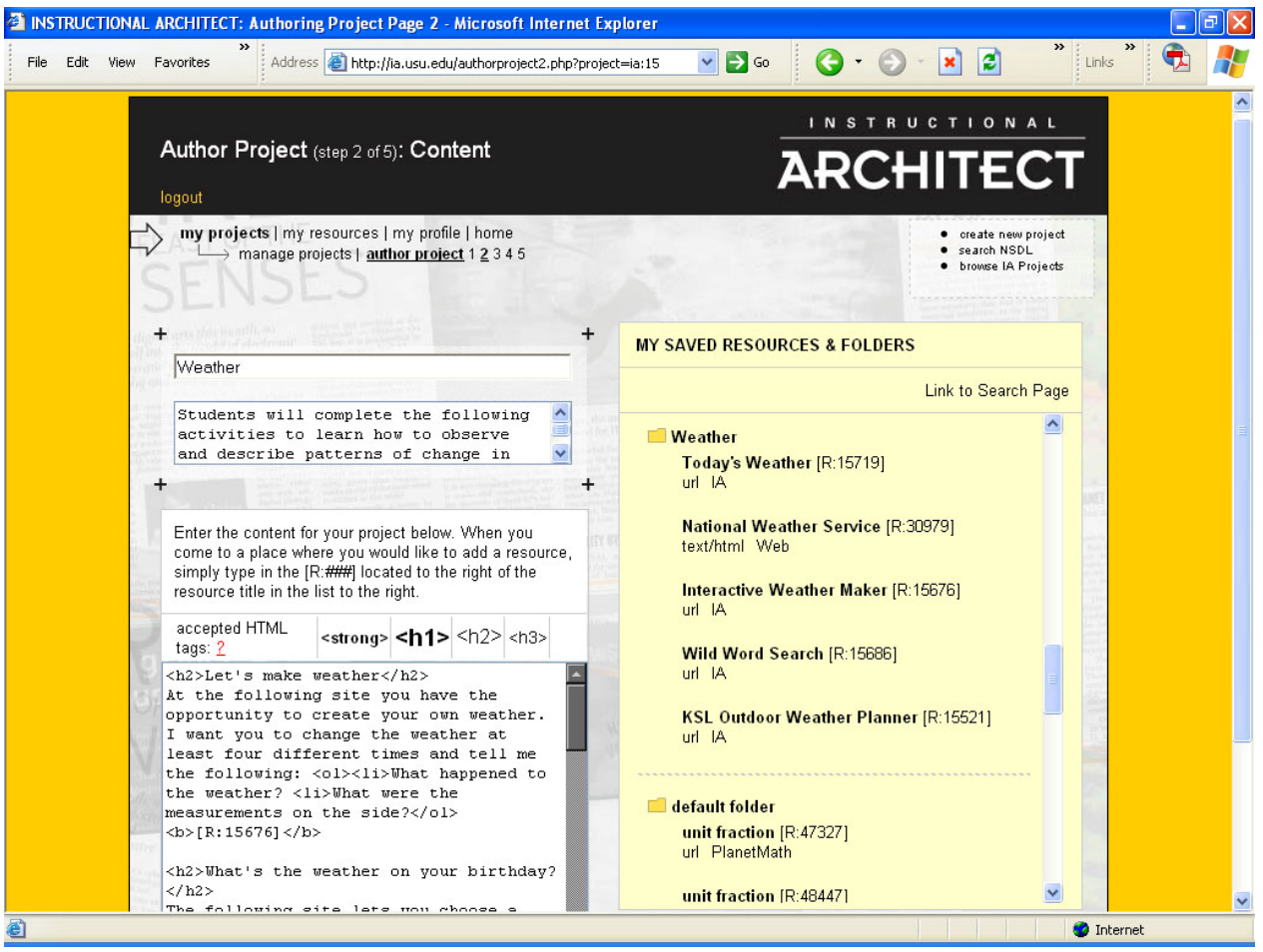

Figure 2: A project under construction, where the user has added text and resources from her saved resource list. 
Finally, users can 'publish' their projects and set permissions on who can view them. The viewing options include user-only, their students, or anyone browsing the IA site. There is also an option to download a SCORM-compliant zip archive of their project for use outside the IA.

An example of a user project can be seen in Figure 3. This user, a middle-school science teacher, was interested in developing a unit on the topic of weather. She located an interactive weather simulator in the Digital Library for Earth System Education (DLESE) (Marlino et al., 2001), an NSDL partner library. Using the IA, she added annotations and directions for her students as part of a homework activity.

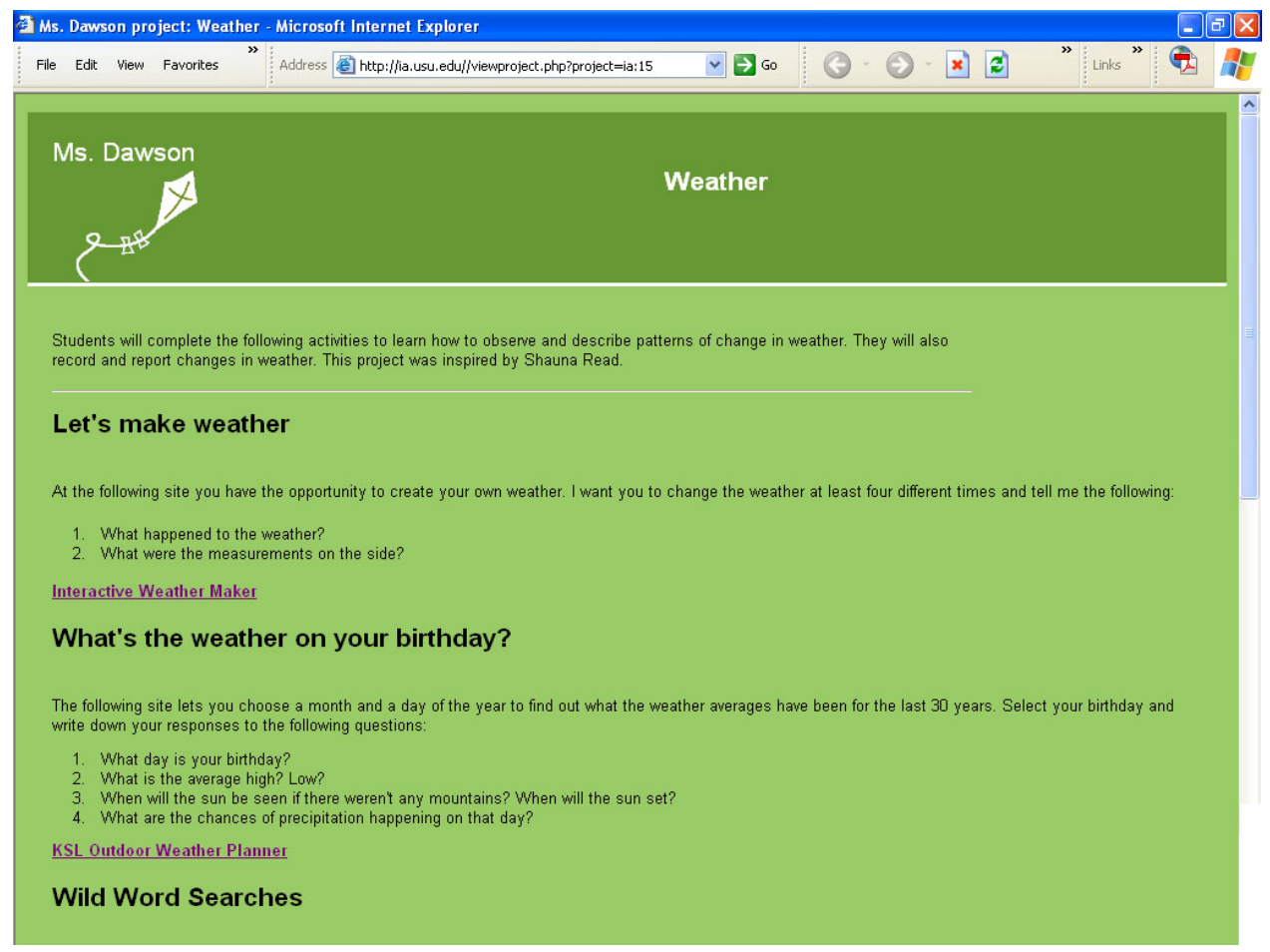

Figure 3: A completed project about weather.

The IA can be used as a portal site in the NSDL, where users can create accounts to store their personal list of resources and projects. IA functionality can also be implemented as a web service using SOAP (Simple Object Access Protocol). The interested digital library simply calls a remote method to pass the metadata of selected learning resources to the IA.

The IA is implemented on a Linux server running the Apache 2.x Web server, using a PostgreSQL 7.x database. PHP (version 5.0) is used for dynamic content generation and communication between the Web server and database. The system has been developed following the open source software model, and the code base is freely available for download (see IA.usu.edu).

\section{DLConnect: A Teacher Professional Development Model}

In recent years, a large body of research and literature documenting what constitutes effective technology-focused teacher professional development has been accruing (Putnam \& Borko, 2000). Findings suggest that effective programs are:

1. Sustained, rather than short in duration (Borko, 2004);

2. Comprised of both workshop (or classroom) teaching and follow-up support; 
3. Complemented with teacher release time to allow for experimentation, implementation, and reflection (Pianfetti, 2001);

4. Tied to incentives to participate;

5. Relevant and/or adaptable to teacher needs, and can be implemented in the teachers' context (Borko, 2004; Pianfetti, 2001);

6. Hands-on with active participation;

7. Collaborative (Borko, 2004; Hoffman \& Thompson, 2000);

8. Design-based (Marx, Blumenfeld, Krajcik, \& Soloway, 1997; Putnam \& Borko, 2000); and

9. Linked to relevant educational standards

The goals of our professional development program are to help teachers learn about the concepts of educational digital libraries, how to search for resources, how to design instructional activities using the Instructional Architect, and how to integrate these capabilities into their teaching practice.

Toward this end, we have been iteratively designing and refining a workshop curriculum for teachers. We also intend to develop follow-up support programs, though these are still in the pilot phases. As such, our current approach addresses all but the first four guidelines. In future work, we plan to extend our approach using both face-to-face and online methods to better provide follow-on support.

Specifically, the workshop curriculum consists of the following components:

1. A motivating example. An interesting learning resource from the NSDL (e.g., an interactive simulation of a frog dissection) is demonstrated to the participants. The example also shows the use of a learning resource in an instructional setting. The specific example is modified to fit the target audience.

2. A description of the NSDL and its mission.

3. Instruction on how to find learning resources in the NSDL, including keyword and Boolean searching, advanced searching, and browsing by collections. Depending on the technical expertise of audience, the amount of modeling is increased or reduced.

4. Participant identify relevant instructional objectives that align to specific core state and national standards for a given subject area. They then practice search techniques to locate resources related to their selected objectives.

5. A discussion on designing activities using learning resources. Participants discuss various methods and topics that could be used to present digital resources to their classrooms. Examples include labs, assignments, interactive group work, research, resource lists, and homework.

6. Instruction on and modeling use of the Instructional Architect, including finding learning resources, browsing projects created in IA by other teachers, creating instructional projects, and publishing projects on the Web. Again, the amount of modeling depends on audience characteristics.

7. Individual participants are provided opportunities for guided practice on creating projects with NSDL learning resources.

8. Lastly, participants share their created projects. 
Thus, by using the IA, and its simple authoring and sharing capabilities, the workshop is designoriented, hands-on, and collaborative. In addition, several aspects of the curriculum (e.g., the examples, the link to educational standards) can be tailored to fit audience and institutional contexts. Finally, the amount of modeling is increased or decreased depending on the technical skill level of the audience.

A complete description of the curriculum is available at http://dlconnect.usu.edu/htm/download.htm.

\section{Implementation Studies}

The design, development, and refinement of the Instructional Architect and the teacher development model have followed a human-centered, iterative design process (Nielsen, 1993). Design, development and evaluation of the Instructional Architect has been ongoing since 2001. Early phases ranged from rapid-prototyping using simple, paper mock-ups to interviews, case studies, observations, and beta tests with participants representative of the target audience.

The workshop model has been undergoing development and testing since Fall 2003. Each workshop implementation was accompanied by an evaluation, so that data collection could inform the next development cycle for the IA, the curriculum, and the evaluation instruments.

Consistent with a human-centered design methodology, the project team has focused on cognitive impacts of the tool and the professional development program, specifically evaluating usability and immediate utility. We devised a framework to guide these evaluation efforts, linking inputs and process variables affecting desired outcomes. In the evaluation literature, this is referred to as a 'program theory' (Patton, 1994; Weiss, 1995). Inputs include factors such as audience characteristics. Outcomes include increased teacher and student use of learning resources from digital libraries. The two key process variables are the IA and the teacher development program.

Results from the evaluation efforts involving over 100 educators indicated that participants were very positive about the value of the NSDL, the quality of the discovered learning resources, the value of the IA, and the value of the workshop. Participants also generally reported that they would recommend the IA to other teachers. Complete findings are described elsewhere (Dorward, Reinke, \& Recker, 2002; Recker et al., 2005).

In this paper, we focus on findings from two workshops, involving 41 mathematics and science teachers. These participants were selected as they were practicing teachers, rather than pre-service teachers or school librarians who comprised the other groups.

In particular, the following research questions are addressed:

- What are the attitudes of teachers regarding the use of learning resources in support of teaching and design?

- How are teachers using learning resources

- How did they design instructional projects using learning resources?

\section{Methods}

\section{Procedure}

Each workshop was conducted in a computer lab where participants sat at an Internet-connected computer. The instructor had a projector to demonstrate the software and design activities to participants. Each workshop also had several staff members, who assisted with questions, noted barriers to effective use of learning resources, and recorded their observations. Workshop duration 
was approximately 6 hours (see Table 1). Participants completed a pre-survey at the beginning of the workshop, and a post-survey at its conclusion.

The survey items included a number of Likert-scaled and open-ended items, that had anchors from $0=$ very low to $4=$ very high $($ mean $=2)$ and could not be left blank. The survey was divided into four parts:

- Demographics (5 questions)

- Attitudes towards computers in education (10 questions). For comparison purposes, these were drawn from a national survey (Becker, 2000).

- Pre-survey to measure teachers' prior knowledge and experience regarding digital libraries and learning resources, their attitudes towards utility of learning resources, and the technology infrastructure in their schools (8 questions).

- Post-survey about participants opinions on the usefulness of the tools, resources, and workshop (20 questions).

The complete list of survey items is available at http://dlconnect.usu.edu/htm/download.htm.

\section{Participants}

Table 1 shows participant demographics for the workshop implementations. Table 2 reports the mean for each group's self-reported level of technology use in the classroom on a scale of 0 to 4 $(0=$ very low; $4=$ very high). Results show that the Workshop A participants reported lower levels of technology use in their schools than Workshop B participants. Similarly, all participants reported having a moderate amount of experience teaching with learning resources, with Workshop A participants reporting less experience than the other group.

Table 1: Participant demographics

\begin{tabular}{|l|c|c|c|c|}
\hline \multicolumn{1}{|c|}{ Workshop } & N & \% female & Mean age & Workshop time (hrs) \\
\hline A. Secondary science & 23 & 47 & 38 & 6 \\
\hline $\begin{array}{l}\text { B. Primary science } \\
\text { and mathematics }\end{array}$ & 18 & 83 & 52 & 6 \\
\hline
\end{tabular}

Table 2: Participant experience ( $0=$ very low; $4=$ very high)

\begin{tabular}{|c|c|c|}
\hline Group & $\begin{array}{c}\text { Tech use } \\
\text { in school }\end{array}$ & $\begin{array}{c}\text { Experience teaching with } \\
\text { learning resources }\end{array}$ \\
\hline A & 1.7 & 2.2 \\
\hline B & 3.4 & 2.8 \\
\hline
\end{tabular}

\section{Findings}

The primary data involved a) qualitative analyses of participants' pre and post workshop comments on electronic surveys, and b) quantitative analyses of projects designed by teachers using online resources and the Instructional Architect. 


\section{Designing using Learning Resources: Participant Views and Attitudes}

Participants' comments on the pre and post-surveys were analyzed by first identifying recurring topics regarding the design of learning activities using learning resources. These topics were then categorized into major themes. Participants' comments were then coded following those themes, as described below. The letters 'A' or 'B' are used to indicate participants' groups, respectively.

We begin by analyzing teachers' comments on the pre-survey.

\section{Convenience or currency of online resources}

Participants offered many comments about the benefits resulting from the ease with which online resources can be accessed. Thus, the possibility of saving time (and money) acted as a motivator. The literature has documented that teachers' are frequently pressed for time (Swain \& Swain, 1999), and it is noteworthy that participants seem to appreciate the way online resources might save them time. Participants also appeared to value the currency of resources, particularly in comparison to textbooks. The value that teachers place on accuracy and currency of online resources has been identified in other research (Sumner, Khoo, Recker, \& Marlino, 2003).

Representative quotes are as follows:

"Gives you quick access to useful tools." (A)

"... helpful to be able to access huge amounts of information compiled for learning." (A)

"It saves time and is easier than other types of research." (A)

"... lots of information quickly." (A)

"It is readily available at no cost." (A)

"Newer info than the 1985 text book we use." (A)

"They are more up to date than any textbook. (A)

\section{Online resources as reference material}

Participants commented on the value of online resources for supporting research. They mentioned that online resources could help increase their own content and teaching knowledge. Participants also seemed aware that many lessons plans were available on the Web for their use.

Representative quotes include:

"... the choices of extensions that are available on the web. They provide lessons that have been tried and tested." (A)

"...stay current in my subject area. Also, sometimes, the explanation in the book is not sufficient so I research better ways to teach the topic." (A)

"They offer new ideas, and more resources than available locally." (A)

"It keeps us current in the changing scientific world." (A)

"It provides you a quick and easy way to find out information." (A)

"Labs and activities are already worked out. Material can be researched right in the classroom." (A)

"The online resources that I use are mostly to facilitate research." (B) 
“... sites to help with lessons, lesson planning, research, encyclopedias, locate pertinent information for particular lessons." (B)

"Online resources might include websites that have information for teacher's knowledge or lesson ideas and plans--information that a student might not use but would be useful to a teacher." (B)

"I know there are thousands of online resource websites that provide lesson plans for teachers." (B)

\section{Online resources as enrichment}

Participants commented on the value of online resources for enriching classroom activities. In this view, online resources were mostly used to enhance an existing activity, or to provide supplemental information for students.

Representative quotes include:

"They offer a far greater selection than available in any junior high library, and kids enjoy learning more when it is connected to a computer." (A)

"Quick, easy reference. Good places to send students for remedial or additional information geared towards their interests."(A)

"Resources that can be used for enhancing education for students." (A)

"Available sites that are readily accessible for teachers to use to enhance classroom instruction." (B)

"These are resources that allow a teacher to find useful information for use in the classroom or to enhance a classroom project." (B)

"Some of the resources are used to provide enrichment to the established curriculum."

(B)

“... sites for students to access to receive up-to-date, accurate information to assist in effective learning" (B)

“... sites I can go to access information or programs for my students. They are also sites with lesson plans I can use or adapt to my needs." (B)

\section{Teacher networking}

A few teachers mentioned the importance of finding out what other teachers are doing. In this way, they supported the idea of using the network to form teacher contacts.

Representative quotes include:

"It is better to be able to go beyond what is local and see how other teachers in other geographical areas are teaching in the same subject areas." (A)

"They can show examples of what other teachers are doing to teach key concepts." (A)

\section{Difficulties in using online resources}

Many teachers commented on difficulties associated with using online resources. Many of these barriers were associated with technical problems. Others also focused on managing and sifting the large amount of content available on the Internet. Interestingly, all the quotes in this category came from teachers in Group A, the group with less access to technology in their schools.

Representative quotes include: 
"If technologically inept this may create a problem." (A)

"...computers not always available, district servers sometimes block needed sites." (A)

" ... difficulties with servers, and a limited number of computers available in schools" (A)

"... sifting through the false and/or opinionated sites. Also, most science sites are designed for high school level or above." (A)

"..too much fluffy stuff." (A)

"There can be a lot of garbage out there." (A)

"Often it takes too long to find things that will work for my classroom. There is so much stuff, it is difficult to find just what I am looking for. Taking the class to the writing lab or media center is a hassle." (A)

"It is at times hard to sift through all the information to find good reliable stuff." (A)

\section{Designing learning activities: Post workshop comments}

After the workshop, we were interested in identifying comments offered by teachers that related to the way online resources could be used to help design learning activities. When asked how they might use the Instructional Architect and the NSDL, teachers noted how these resources could be used to create new and unique opportunities for students.

Representative quotes include:

"Many things can be brought into the classroom that would otherwise be unavailable."

(A)

“... Articles, labs, assignments, activities for teachers and students, (for example, the Virtual Frog dissection)" (A)

"It is essential to stay current and to provide a variety of opportunities for students to learn and review." (A)

“... teachers [can] choose reputable links and combine them with simple instructions to create a student learning experience on the web." (B)

" ...you can organize these online resources and include information and instructions about how to use each of the resources in a meaningful way." (B)

“... we can create projects for students using online resources." (B)

"I used the idea that it would be beneficial and a learning experience for my students in regards to magnets and electricity. Did it encourage learning and exploration?" (B)

Many teachers, however, only foresaw simple uses of the tools and resources. Thus, after the workshop, teachers appeared to note few ways the tools and resources could significantly influence their teaching practice.

Representative quotes include:

"[The IA is] an online lesson planner or student guide of appropriate sites to visit for a specific subject." (A)

"A way to make web pages of links" (A)

"A way for the teacher to post information and links to resources for students to use." (B) 
"A teacher can make a collection of online resources that students can access to use for practice or research." (B)

"Online resources I would use with Instructional Architect are mainly websites with information or activities that students could use to learn information or practice skills." (B)

Finally, one teacher acknowledged the limitations of the workshop format, with this quote: "I don't think the quality of the project I created was exceptional. I need more time to create the purpose and objective of the activity." (B)

\section{Designing using Learning Resources: Project Analysis}

The instructional projects created by IA users offer a unique and convenient window into understanding how teachers used digital library learning resources. While analyses of server and query logs can reveal user search terms and resource downloads, IA projects show how users organize and design with learning resources.

Table 3 shows the number of accounts and projects created by participants in the two groups. Teachers in the first group created a mean of 1.1 projects, while teachers in the other group created 1.8. This suggests greater use by the teachers with better technology infrastructure in their schools.

Table 3. Project, accounts, and resource usage for different participant groups

\begin{tabular}{|c|c|c|c|}
\hline Group & $\begin{array}{c}\text { \# of accounts } \\
\text { created }\end{array}$ & $\begin{array}{c}\text { Mean \# of projects } \\
\text { per account }\end{array}$ & $\begin{array}{c}\text { Maximum number of } \\
\text { projects per account }\end{array}$ \\
\hline A & 23 & 1.1 & 3 \\
\hline B & 18 & 1.8 & 7 \\
\hline
\end{tabular}

\section{Discovery strategies}

An analysis of terms used to search the NSDL showed that the vast majority (approximately $85 \%$ for both groups) of queries was comprised of just one keyword. This finding has been documented in the literature (Soloway \& Wallace, 1997; Wallace, Kupperman, Krajcik, \& Soloway, 2000). In addition, the advanced search feature was almost never used. This suggests that teachers are using simple strategies to fuel the design of their projects.

\section{Origin of resources}

In response to user requests, we added a feature to the IA whereby non-digital library resources (i.e., Web URLs) can be inserted in IA projects. Table 4 shows the origin of resources used by participants in their projects. Overall, participants in Group A used a higher percent of resources from the NSDL, whereas Group B participants seemed to prefer to use Web resources.

Table 4. Origin of Resources

\begin{tabular}{|c|c|c|c|c|}
\hline \multirow{2}{*}{ Origin } & \multicolumn{2}{|c|}{ Group A } & \multicolumn{2}{c|}{ Group B } \\
\cline { 2 - 5 } & Frequency & Percent & Frequency & Percent \\
\hline NSDL & 58 & 80.6 & 39 & 39.8 \\
\hline WEB & 14 & 19.4 & 67 & 60.2 \\
\hline Total & 72 & 100 & 106 & 100 \\
\hline
\end{tabular}


Although Table 4 shows that Web resources comprised a large proportion of resources used, it is an overestimate. In our observations, we noted that often participants located a resource within a digital library (at a lower level of granularity than cataloged), and then copied and pasted that URL into their project. From a database point of view, although this resource was discovered within an NSDL digital library, it simply appears as a Web resource (without accompanying metadata).

We conducted a simple experiment to estimate this error. Ten percent of the Web resources were randomly selected and then manually checked to see if they originated from an NSDL partner digital library. Results suggest that just over $70 \%$ of these Web resources were 'most likely' from an NSDL partner library. As such, NSDL resources appear to be of high value to participants. Yet, participants (especially in Group B) often preferred to use these at a lower level of granularity than cataloged by the library.

\section{Granularity of resources}

To estimate the granularity (or size) of learning resources used in participants' projects, ten percent of the NSDL resources were randomly selected and then manually coded into one of three categories: small, medium, or large granularity. Small granularity was defined as a simple animation or lesson plan. Medium granularity was defined as consisting of a set of web pages with more specific topics, consisting of multiple format types (e.g., text, images, etc). Finally, large granularity was defined as an entire website, typically consisting of several topics.

Results show that $38 \%$ of these NSDL resources had small granularity, whereas $21 \%$ were medium and 24\% were large (see Table 5). Unfortunately, at the time of the analysis, $17 \%$ of the resources were not available due to either a network time-out or a broken link. As also suggested by the previous analysis, participants preferred NSDL resources at a lower level of granularity.

Table 5: Granularity of Resources

\begin{tabular}{|c|c|}
\hline Granularity & Percent \\
\hline Small & 38 \\
\hline Medium & 21 \\
\hline Large & 24 \\
\hline Not available & 17 \\
\hline
\end{tabular}

\section{Discussion}

Overall, participants mentioned many potential benefits of using online resources in support of their teaching. They mentioned the convenience, currency, and networking potentials of online resources. In terms of creating learning activities for their students, the most common use mentioned was for enrichment purposes. Many participants saw an important role for online resources for enhancing planned activities. However, despite this enthusiasm, analyses of IA usage showed generally low post-workshop use of the system. This was especially true for participants in Group A, who reported lower access to technology in their schools.

Participants also identified barriers in using online resources. These included lack of technology access and literacy. Participants also mentioned difficulties in managing the overabundance of resources and their varying quality. Participants in Group A, the low-technology access group, more frequently noted these barriers. 
The frequency with which participants mentioned accessing online resources for research purposes was an unanticipated finding. Participants described the important role of online resources in furthering their scientific knowledge as well as their teaching knowledge. This potential has been advocated by other researchers (Davis \& Krajcik, 2005).

In the post-workshop survey, some participants noted how online resources could be used to create opportunities for students that were never before possible. They mentioned many kinds of instructional situations that could use such resources. Coupled with these comments, analyses of IA projects showed that participants seemed to prefer to use small granularity resources. Thus, participants seemed to be creating simple projects with somewhat directed activities. This, of course, may be a result of the fact that the participants were novice users.

Other teachers, however, seem to view the tools and resources as simply another technological tool to potentially add to their repertoire. They did not appear to view these as opportunities for the design of learning activities.

\section{Limitations and Future Work}

This research has several limitations, including a) participant self-selection, b) the use of selfreport survey data, and c) the lack of follow-up. In this section, we briefly address these problems.

First, participants in the workshop chose to engage in professional development opportunities. As such, it is not possible to generalize findings to all teachers. A more rigorous study would involve a randomly selected sample of teachers who varied in terms of comfort with information technology, the Internet, and the design of activities using learning resources.

Second, some conclusions were based on self-report survey data, which may be subject to recall bias and hence under-reported or over-reported. In particular, due to the halo effect, participants possibly overstated the value and potential of learning resources and tools.

Third, little contact occurred with participants after the workshop. While our web server log files reported subsequent use of the IA, we don't know much about how teachers subsequently designed projects and how they were used (if at all) in classrooms. And, of course, we were unable to track other use of Web resources and the NSDL.

In ongoing work, we are conducting follow up interviews and classroom observations with workshop participants to better understand teacher design. We are also conducting classroom observations to document how teachers design and use of learning resources in learning activities. These studies will inform research designs for future studies investigating impact on students.

\section{Conclusion}

In this paper, we described characteristics of the Instructional Architect and a professional development program designed to introduce teachers to online learning resources and tools. In particular, we identified characteristics of workshop design that are consistent with best practices in professional development. In addition, we noted out how on-going evaluation continues to inform refinement of tools, and workshop content and process.

We also reported on analyses of both quantitative and qualitative data collected as two groups of teachers participated in professional development workshops. In the workshops, participants learned to use an educational digital library (the NSDL), and an end-user authoring tool (the Instructional Architect) that supports the creation of instructional projects using online resources.

Triangulating different data sources provided clear advantages. While analyses of participant comments noted the many potential advantages of online resources, projects analyses revealed 
that participants designed a small number of fairly simple projects using resources with small granularity. However, we know little about how IA projects and learning resources were subsequently used (if at all) in classroom contexts.

This paper also presented an image of teaching as design. In particular, we sought to understand the extent to which participants view their practice and their use of online resources as an opportunity to design learning activities for their students. Limitations in the design of the empirical studies mean that findings cannot be generalized to the larger teacher population. However, they do provide preliminary insights on the role of teacher design.

In the future, we plan to continue development of teacher tools and workshops to help teachers learn to use NSDL resources in ways that enable them to create meaningful student activities, while also increasing their skills as instructional activity designers. Additionally, by accessing, assessing, and using learning resources in sustained ways, teachers may increase their own content and teaching knowledge.

\section{Acknowledgements}

This material is based upon work supported in part by the National Science Foundation under Grants No. 0333818 \& 0434892, and Utah State University. Any opinions, findings, and conclusions or recommendations expressed in this material are those of the authors and do not necessarily reflect the views of the National Science Foundation. We thank the teachers who participated in our studies.

\section{References}

Agre, P. (2003). Information and institutional change: The case of digital libraries. In A. Bishop, N. Van House \& B. Buttenfield (Eds.), Digital library use: Social practice in design and evaluation (pp. 219240). Cambridge, MA: The MIT Press.

Becker, H. (2000). Findings from the teaching, learning, and computing survey. Education Policy Analysis Archives, 8(51).

Borko, H. (2004). Professional development and teacher learning: Mapping the terrain. Educational Researcher, 33(8), 3-15.

Brown, M., \& Edelson, D. (2003). Teaching as design: Can we better understand the ways in which teachers use materials so we can better design materials to support their change in practice? (Design Brief). Evanston, IL: Center for Learning Technologies in Urban Schools.

Cuban, L. (2001). Oversold and underused: Computers in the classroom. Cambridge: Harvard University Press.

Davis, E., \& Krajcik, J. (2005). Designing Educative Curriculum Materials to Promote Teacher Learning. Educational Researcher, 34(3), 3-14.

Dede, C. (2003). The role of emerging technologies for knowledge mobilization, dissemination, and use in education. Retrieved April 8, 2005, from http://www.virtual.gmu.edu/EDIT895/knowlmob.html

Dorward, J., \& Heal, R. (1999). National Library of Virtual Manipulatives for Elementary and Middle Level Mathematics. In Proceedings of Webnet99 (pp. 1510-1512). Charlottesville, VA: AACE.

Dorward, J., Reinke, D., \& Recker, M. (2002). An evaluation model for a digital library. In Proceedings of Joint Conference of Digital Libraries (pp. 322-323). New York: ACM.

Dublin Core Metadata Initiative. (2002). DCMI Education Working Group. Retrieved 9 January, 2003, from http://dublincore.org/groups/education/

Friesen, N. (2003). Three objections to learning objects. In R. McGreal (Ed.), Learning Objects and Metadata. London: Kogan Page. 
Hoffman, E., \& Thompson, G. (2000). Putting the research to work: Professional development models from Michigan. Tech Trends, 44, 20-23.

Lagoze, C. (2002). Core Services in the Architecture of the National Digital Library for Science Education (NSDL). In Proceedings of Joint Conference of Digital Libraries (pp. 201-209). New York: ACM.

Marlino, M., Sumner, T. R., Fulker, D., Manduca, C., \& Mogk, D. (2001). The digital library for earth system education: Building community, building the library. Communications of the ACM, 44(5), 80-81.

Marx, R., Blumenfeld, P., Krajcik, J., \& Soloway, E. (1997). Enacting project based science. Elementary School Journal, 97(4), 341-358.

Nielsen, J. (1993). Usability engineering. San Francisco: Morgan Kaufmann.

O'Day, V., \& Nardi, B. (2003). An ecological perspective on digital libraries. In A. Bishop, N. Van House \& B. Buttenfield (Eds.), Digital Library Use: Social Practice in Design and Evaluation (pp. 65-84). Cambridge: MA: The MIT Press.

Patton, M. (1994). Developmental evaluation. Evaluation Practice, 15(3), 311-319.

Pianfetti, E. (2001). Teachers and technology: Digital literacy through professional development. Language Arts, 78(3), 255-262.

Putnam, R., \& Borko, H. (2000). What do new views of knowledge and thinking have to say about research on teacher learning? Educational Researcher, 29(1), 4-15.

Recker, M., Dorward, J., Dawson, D., Halioris, S., Liu, Y., Mao, X., et al. (2005). You can lead a horse to water: Teacher development and use of digital library resources. In Proceedings of the Joint Conference on Digital Libraries (pp. 1-9). NY, NY: ACM.

Recker, M., Dorward, J., \& Nelson, L. (2004). Discovery and use of online learning resources: Case study findings. Educational Technology \& Society, 7(2).

Recker, M., Dorward, J., \& Reinke, D. (2003). Development and evaluation of digital library services: Theory and practice. In M. Mardis (Ed.), K12 digital libraries (pp. 107-119). Syracuse: ERIC.

Soloway, E., \& Wallace, R. (1997). Does the internet support student inquiry? Don't ask. Communications of the ACM, 40(5), 11-16.

Sumner, T., Khoo, M., Recker, M., \& Marlino, M. (2003). Understanding educator perceptions of "Quality" in digital libraries. In Proceedings of Joint Conference of Digital Libraries (pp. 269-279). New York: ACM.

Swain, M., \& Swain, S. (1999). Teacher time (or rather, the lack of it). American Educator, 23(3), 20-26.

Wallace, R., Kupperman, J., Krajcik, J., S, \& Soloway, E. (2000). Science on the Web: Students online in a sixth-grade classroom. Journal of the Learning Sciences, 9(1), 75-104.

Wattenberg, F. (1998). A national digital library for science, mathematics, engineering, and technology education. Retrieved 29-Dec-2002, from http://www.dlib.org/dlib/october98/wattenberg/10wattenberg.html\#contents

Weiss, C. (1995). Evaluation. Upper Saddle River, NJ: Prentice Hall.

Wiley, D., Recker, M., \& Gibbons, A. (2000). In defense of the by-hand assembly of learning objects. Retrieved 23 May, 2005, from http://wiley.ed.usu.edu/writings/

Zia, L. (2001). Growing a national learning environments and resources network for science, mathematics, engineering, and technology education: Current Issues and Opportunities for the NSDL Program. Retrieved 17 July, 2003, from http://www.dlib.org/dlib/march01/zia/03zia.html 


\section{Biographies}

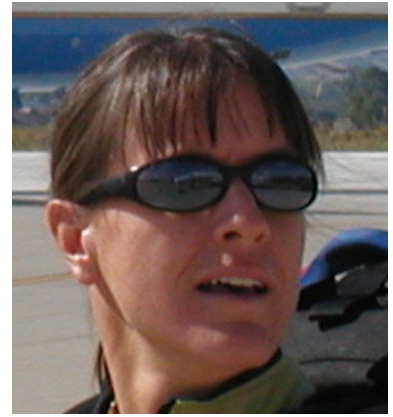

Mimi Recker is Associate Professor in the Department of Instructional Technology at Utah State University, in the beautiful mountains of Northern Utah. In two current NSDL grants, her research group is developing software tools, professional development programs, and sustainable dissemination strategies so that teachers and learners can make better use of online learning resources to help improve learning. She received her Ph.D. from the University of California, Berkeley, and held academic positions at the Georgia Institute of Technology and Victoria University of Wellington, New Zealand.

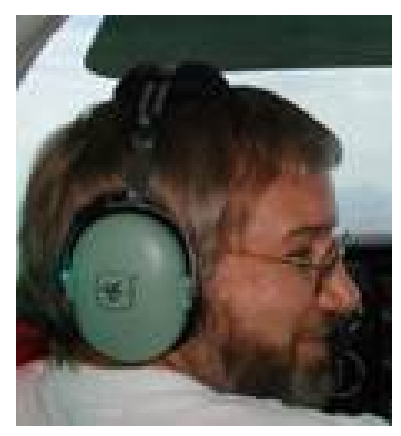

Jim Dorward is an Associate Professor in the Department of Elementary and Middle Level Education at Utah State University. He specializes in Program Evaluation, Research Methods, and Mathematics Education. Dr. Dorward has published widely in mathematics education and evaluation journals and been principal investigator and project evaluator on several large-scale national projects. Currently, he is CoPI on an evaluation capacity-building project with NSF's Math, Science Partnership program, an Instructional Materials Development project, and a National Science Digital Library (NSDL) service project. He also serves on NSDL's Evaluation and Impact Standing Committee. Jim enjoys all outdoor pursuits and spent 15 seasons a climbing ranger in Grand Teton National Park. He was awarded the Department of Interior's Valor Award for helping save the life of a seriously injured climber in a rather dramatic rescue in 1992. He is also a private pilot with a host of excuses for flying in the mountains and deserts of the West. He received his Doctorate in Education at the University of Oregon specializing in program evaluation and science education.

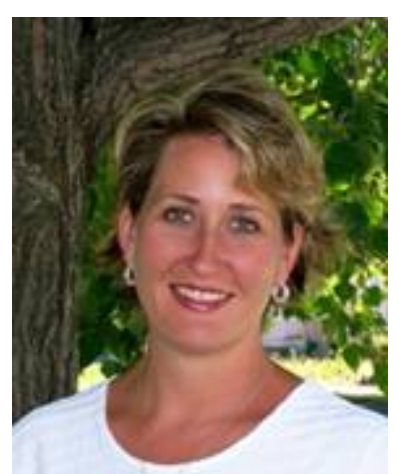

Deonne Dawson is a third-year Ph.D. student in the Department of Instructional Technology at Utah State University. Her interests include online learning resources, digital libraries, and bringing technology into the classroom. As a member of the Instructional Architect (IA) team, Deonne is primarily responsible for developing, organizing, and facilitating workshops. Additionally, she is notorious for paying attention to details and bringing a sense of humor to the team. Deonne earned the title of Microsoft Queen during her first year of coursework at USU and has taught Microsoft classes for the past eight years. She continues to teach summer workshops for USU. Before moving to Logan to pursue her doctorate, Deonne taught the Microsoft Office Suite in her hometown, Kalispell, MT, at Flathead Valley Community College. Prior to teaching at FVCC, she taught similar classes at a private vocation college, Interface Computer School, located in Spokane, WA. Deonne received a Master of Arts in Teaching: Teaching At-Risk Students from Gonzaga University (2000), a Bachelors of Business Administration: Marketing from Idaho State University (1992) and an Associate in Arts and Sciences: Computer Information Systems from Brigham Young University-Idaho (1990). 


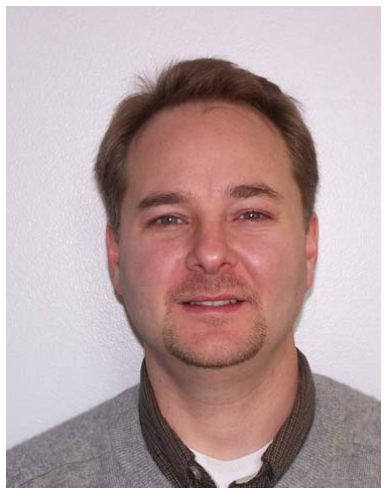

Sam Halioris is a fourth-year student in the Research and Evaluation Methodology (REM) combined Master's and Ph.D. program in the Department of Psychology at Utah State University. His focus is on instrument development with applications in the educational use of online resources as well as human attitudes about advanced robotic and computer-based inference-making devices. As a member of the Instructional Architect (IA) team, Sam is primarily responsible for collection and analysis of data to assess the effectiveness of IA, NSDL, and IA workshops; as well as the development of a theoretical framework and measurement instrument to help educators understand the quality of online resources for education. Before moving to Logan, Utah, in 2001 to pursue his Ph.D. Sam earned an undergraduate degree in Electrical Engineering from the University of Arkansas (1993). Beginning in 1994 he worked for Dow Jones \& Company for three years building online information systems for stock market investors. In late 1997, Sam moved to Hong Kong, China to start an online information company for Asian stock market investors.

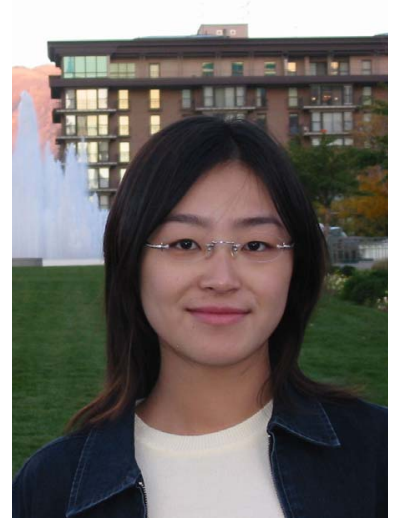

Xin Mao is a second-year Ph.D. student in the Department of Instructional Technology at Utah State University (USU). Her research interests mainly include web-based training, digital libraries, and learning in online environments. As a member of the Instructional Architect (IA) team, Xin Mao is primarily responsible for doing a webmetrics analyses of participant usage of NSDL resources and Instructional Architect. Additionally, she is responsible for building and maintaining the DLConnect website and doing literature review on the upcoming online workshop curriculum for the DLConnect project. Xin loves everything that can bring beauty and delight. She enjoys designing multimedia materials like web pages, pictures, animations and videos. She also likes dealing with statistics. She is familiar with Micromedia Dreamweaver, Flash, Fireworks, Adobe Photoshop, SPSS and video shooting and editing tools. Xin received a Master of Education (2003) and a Bachelor of Science (2000) both in Instructional Technology and from the department of information technology, Central China Normal University of China. Before Xin came to the United States she worked as a research assistant and taught part-time.

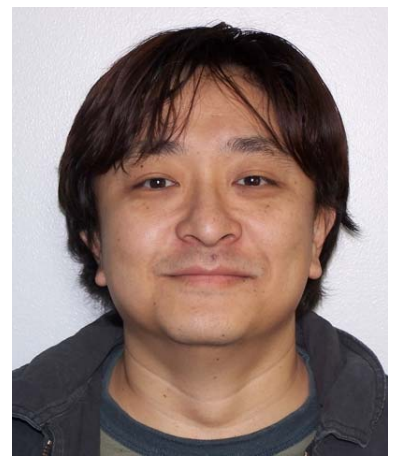

Jaeyang Park is a Ph.D. student in the department of Instructional Technology at Utah State University. He is involved in Instructional Architechure project as a programmer. His main research subject is Instructonal Design Language. He's also interested in Digital Library, Learning Object, and industry standards for e-Learning like SCORM, IMS Simple Sequencing, IMS Learning Design, and so forth. Aside from Instructional Technology field, Jaeyang loves to learn new programming lanugages, and exploring new operating systems. He can code in $\mathrm{C}, \mathrm{C}++, \mathrm{CH}$, Objective-C, Java, and PHP while maintaining a good understanding of basics of other languages like Smalltalk, Perl, Groovy, Python, x86 Assembly, Prolog, and others. Jaeyang got a Master's degree in Instructional Technology from Utah State University and a Bachelor's degree in Computer Science in Pusan National University of Korea. 


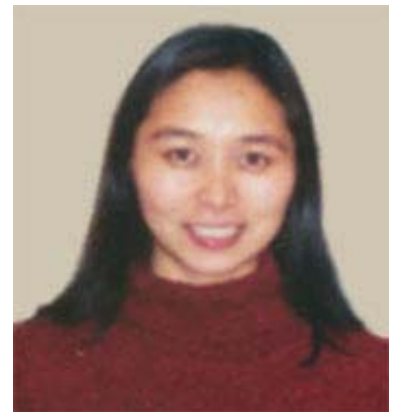

Ye Liu is a second-year Ph.D. student in the Department of Instructional Technology at Utah State University (USU). Her main research interests include web-based learning, digital libraries, cognitive load theory, and improving learning with web accessibility. She is a programmer in the Instructional Architect (IA) team. Ye loves playing with fun stuff such as php, javascript, css, flash, photoshop, and video editing. She also enjoys reading stories with her lovely 5-year-old daughter. Ye received Master of Science degrees from Utah State University; Business Information Systems (2002) and Instructional Technology (2003). Before she came to the United States to enjoy student life again, she worked at the Bank of China and Law School, Jilin University after she got a J.D. (1992) and L.L.M. (1995) from Law School, Jilin University in China.

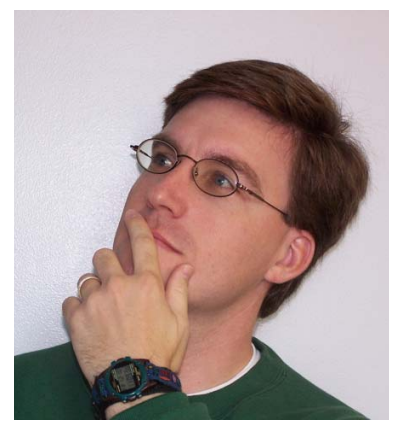

Bart Palmer is beginning his Ph.D. coursework in Instructional Technology at Utah State University. Working on the Instructional Architect as a programmer and exposure of IA metadata has provided experience organizing and presenting meaningful information about digital resources. Coursework has been in areas of digital community development and sustainability, with some thinking about immersive instructional environments on the side. He recently finished an internship at Brigham Young University-Hawaii where he has worked to develop the new Center for Instructional Technology \& Outreach department. His academic interests include just about everything from programming to simulations, to open sharing of educational resources and experiences, to concept maps, and much more. While earning his Bachelors in Computer Science from Brigham Young University-Provo, Bart worked on porting the functionality of TICCIT--developed in the early 70s--to a web application called CLIPS. 